\title{
Author Correction: Fabrication of microfluidic device for Aflatoxin M1 detection in milk samples with specific aptamers
}

\section{Aruna Kasoju, Deepshikha Shahdeo, Azmat Ali Khan, Narlawar Sagar Shrikrishna, Subhasis Mahari, Amer M. Alanazi, Mashooq Ahmad Bhat, Jyotsnendu Giri \& Sonu Gandhi}

Correction to: Scientific Reports https://doi.org/10.1038/s41598-020-60926-2, published online 13 March 2020

The original version of this Article contained errors.

Affiliation 3, was incorrectly given as 'Department of Pharmaceutical Chemistry, King Saud University, Riyadh, 11451, Saudi Arabia. The correct affiliation is listed below:

Department of Pharmaceutical Chemistry, College of Pharmacy, King Saud University, Riyadh, 11451, Kingdom of Saudi Arabia.

Additionally, the title for Table 1 was incorrect.

'Comparison of different techniques for the detection of Aflatoxin in mi.'

now reads:

'Comparison of different techniques for the detection of Aflatoxin in milk.'

The Supplementary Information file contained a typographical error in the spelling of the author Azmat Ali Khan, which was incorrectly given as Azamat Ali Khan.

Additionally, in the Supplementary Information file,

"Figure S1. (a) Image of different concentration of Ochratoxin in water; (b) Microfluidic device ( $\mu$ PAD) for the detection of Aflatoxin M1 and Ochratoxin in milk; (i) presence of Aflatoxin M1aptamer led to aggregation of AuNPs and (ii) in presence of Ochratoxin aptamer, no aggregation occurred due to non-specificity with Aflatoxin M1."

now reads:

"Figure S1. (a) Image of different concentration of Ochratoxin in water; (b) Microfluidic device ( $\mu$ PAD) for the detection of Aflatoxin M1 and Ochratoxin in milk; (i) presence of Aflatoxin M1aptamer led to aggregation of AuNPs and (ii) in presence of Ochratoxinaptamer, no aggregation occurred due to non-specificity with Aflatoxin M1."

These errors have now been corrected in the HTML and PDF versions of the Article and in the Supplementary Information file that accompanies the article. 
(c) (i) Open Access This article is licensed under a Creative Commons Attribution 4.0 International License, which permits use, sharing, adaptation, distribution and reproduction in any medium or format, as long as you give appropriate credit to the original author(s) and the source, provide a link to the Creative Commons license, and indicate if changes were made. The images or other third party material in this article are included in the article's Creative Commons license, unless indicated otherwise in a credit line to the material. If material is not included in the article's Creative Commons license and your intended use is not permitted by statutory regulation or exceeds the permitted use, you will need to obtain permission directly from the copyright holder. To view a copy of this license, visit http://creativecommons.org/licenses/by/4.0/.

(C) The Author(s) 2020 